\title{
THE CONNECTION BETWEEN DIGITAL DIVIDE AND SOCIAL EXCLUSION: IMPLICATIONS FOR SOCIAL WORK Thommy Sebatana Molala ${ }^{*}$, Jabulani Calvin Makhubele ${ }^{2}$ \\ ${ }^{1 *, 2}$ Department of Social Work, University of Limpopo, Private Bag x 1106, Sovenga, 0727, South Africa. Email: ${ }^{1 *}$ molalathomas@gmail.com, ${ }^{2}$ jabulani.Makhubele@ul.ac.za
} Article History: Received on $30^{\text {th }}$ July 2021, Revised on $17^{\text {th }}$ August 2021, Published on $20^{\text {th }}$ August 2021

\begin{abstract}
Purpose of the study: This paper aims to ascertain the nexus between the digital divide and social exclusion (inequalities) - directly and indirectly, as digital technology enables people to socialise, communicate, work, study, and conduct business.
\end{abstract}

Methodology: To do this, the literature review is employed as a methodology. Specifically, the narrative or semisystematic literature review was conducted on all sources germane to the topic under investigation.

Main findings: The paper has found that the digital divide has adverse effects on the employment, education, health, social services, and socio-economic development of digitally excluded people. In addition, it has emerged that the digital divide exacerbates social exclusion.

Applications of this study: To this end, Social Workers and associated professionals are empowered with knowledge about the role of the digital divide in social exclusion, thus they are expected to play active assume advocacy roles as far as Information Communication Policies are concerned.

Novelty/Originality of this study: Digitalisation has embedded factors inducing poverty, inequity, and discrimination unintentionally; thereby this paper replenishes literature in Social Science to enable Social Scientists to utilise relevant information -in their research, intervention, and commentary.

Keywords: Social Work, Digital Divide, Unemployment, Inequality, Poverty.

\section{INTRODUCTION}

Conceptualising and developing one's research on and relating it to existing knowledge is the essential and foundational structure of all academic research activities. This exercise should have a clear and precise strategy which should include selection criteria for search. The methodology should be described well enough for another researcher to duplicate the process selected literature should be analysed. It should not be more of summarizing articles, comparing groups of articles, or just for identification of themes or gaps (Whittemore \& Knaf, 2005). Therefore, in this article, the literature review was conducted to establish the connection between the digital divide and social exclusion. Technological advancement has brought new ways in all spheres of human life, however, parallel to these virtuoso innovations, unintended horrendous consequences crop out. The use of technology in society is ubiquitous and permeates all aspects of life. Some authors have postulated that technology enables people to communicate, interact, work, study, and conduct business (Soomro et al., 2020). This, therefore, considering the digital age, implies that access to technologies and the internet are necessities and prerequisites for development in society. However, structural forces impede access to these necessities in society and creates another wall of inequality, as it is the case with other resources in society. The disproportional access gives rise to a phenomenon referred to as the digital divide. The digital divide is the disparities in access to Information Communication Technology (ICT) devices, infrastructure among people, countries, and regions (Turianskyi, 2020). South Africa seems to be doing well with accessing ICT devices, however, Gillwald et al. (2018) lament that data in the country remains one very expensive compared to other countries. The digital divide also involves the disproportional digital skills and competencies between people and the majority who bear the brunt of this digital divide are those who are from far-flung areas without ICT infrastructure, let alone ICT devices and rural or underresourced communities. In harmony, Van Dirk (2005) concurs by averring that the digital divide is an aspect of social inequalities. The digital divide is one of the most pertinent and ghastly developmental challenges facing the world. Social inequalities as the result of the digital divide become a fertile ground to breed and perpetuate social exclusion in a society.

Social exclusion is a major human rights issue globally and manifest itself through abject poverty, disproportional unemployment levels, and inequalities. Social exclusion is a result of people being deprived of opportunities due to structural challenges. According to Stewaert (2004), deprivations reinforce each other i.e. lack of education induces low incomes which inhibits people from addressing other deprivations in housing, health, and society Social exclusion entails the deprivation of people to participate in the economy, political, social, health and cultural activities (Berafe, 2017). In support of Berafe's description of social exclusion, Khan (2012) avows that that social exclusion is multidimensional as it encompasses lack of employment, justice, political voice, economic participation, and social relationships. Social exclusion is the worst of social injustice. Therefore, deprivation of access to ICT devices, and infrastructure results in inaccessibility to crucial opportunities for learning, employment, and economic advancement. Consequently, the digital divide breeds poverty. 
The connection between the digital divide and social exclusion has not received adequate attention in the social sciences. Hence, this paper seeks to review literature in order to understand the contribution of the digital divide towards social exclusion, which relegates people to the periphery of society. The emergence of the digital divide has been treated purely as Information Communication Technology rather than a multidimensional societal issue. The proliferation of the use of technology has inadvertently exacerbated inequalities in society. These inequalities are set to worsen social exclusion, thus necessitating a scholarly interrogation to find solutions for humanity.

\section{The objective of the study}

This paper aims to ascertain the nexus between the digital divide and social exclusion (inequalities) - directly and indirectly, as digital technology enables people to socialise, communicate, work, study, and conduct business.

\section{LITERATURE OVERVIEW ON DIGITAL DIVIDE GLOBALLY}

As it has been stated that the literature review approach was adopted for this study, this approach can be narrowed down to investigating the effect of or relationship between two specific variables, hence the connection between the digital divide and social exclusion. Besides, some authors, Baumeister and Leary (1997) and Torraco, (2005) averred that literature reviews are useful when the aim is to provide an overview of a certain issue or research problem. Usually, authors postulate that this type of literature review is conducted to evaluate the state of knowledge on a particular topic. As a result, it can be used, to create research agendas, identify research gaps, or simply discuss a particular matter. Literature reviews can also be useful if the aim is to engage in theory development. Furthermore, Snyder (2019) posits that in these cases, a literature review provides the basis for building a new conceptual model or theory, and it can be valuable when aiming to map the development of a particular research field over time. Specifically, the nexus and relevance of digitisation in social science service provisions in the quest to address socio-economic challenges faced by the disadvantaged, particularly, during the COVID-19 pandemic.

In consideration of the above, there have been concerted efforts to expand the internet globally due to the advent of globalisation and digitalisation of economic, social, health, and related services. The International Telecommunications Union [ITU] (2020) notes that while there has been rapid growth in internet penetration over the last five years - about half of the world population is not connected to the internet. The number of people who do not have access to the internet is highly concentrated in the least developed countries i.e. Sub-Saharan Africa, South Asia, and East Asia/Pacific are beset lack of ICT infrastructure and economic opportunities (ITU, 2020; GSMA, 2020; Independent Communication Authority of South Africa, 2020). The slow development of third world countries is not only limited to ICT development as it applies to other aspects, but ICT seems to be the glue that binds all developmental initiatives together.

On the contrary, developed countries account for the highest number of connected people, which can be attributed to ICT infrastructure penetration, and economic performance (Broadband Commission, 2019). The disparities in internet connectivity between well-developed and least developed countries have socio-economic implications. It has been reported by United Nations [UN], (2021) that there is a positive correlation between internet connectivity and economic growth (. A few years ago, Organisation for Economic Co-operation and Development [OECD] (2016), avowed that technology plays an integral part in commerce, education, agriculture, health, and social development, thus connectivity is a prerequisite to participate in the digital economy. It is also anticipated that disproportional access to the internet between well-developed and least developed countries will entrench uneven socio-economic development. The digital divide is likely to plunge least developed countries into poverty, and exacerbate social exclusion in those countries. On the health front, the emergence of COVID-19 has necessitated and expedited the use of digital technologies in education, employment, entertainment, governance, health, and social services. Metaphorically, in Orwellian language, it means that only those with a connection to the internet can access services, while others are excluded.

The digital divide deepens existing inequalities in society in spite of all efforts both public and private institutions are investing in developmental agendas. The internet has become an educational necessity, thus lack of internet is likely to preclude young people from deprived backgrounds. On the employment front, recruitment processes have been digitalised, and this means only those with connectivity are likely to find employment at the expense of their unconnected counterparts. From the above, it is deducible that the lack of access to the internet can inhibit people from advancing in life by excluding them from mainstream societal activities.

\section{METHODOLOGY}

Due to the nature of the central thesis of this article, it was felt significant and prudent that literature review as the methodology to be employed. A literature review can broadly be described as a more or less systematic way of collecting and synthesizing previous research (Baumeister \& Leary, 1997; Tranfield, Denyer, \& Smart, 2003). An effective and well-conducted review as a research method creates a firm foundation for advancing knowledge and facilitating theory development (Webster \& Watson, 2002). Syder (2019) phases of literature review has been adopted for this article and they are as follows:

Phase 1: Designing the Review - For the purpose of this article, narrative or semi-systematic literature review was used because the idea was to establish a connection between digital divide and social exclusion and how social service 
professionals (social workers) could assist in advocating for the accessibility and utilisation of technological devises and internet. More than half of the decade, Wong et al. (2013) opined that the semi-systematic or narrative review approach is designed for topics that have been conceptualized differently and studied by various groups of researchers within diverse disciplines and that hinder a full systematic review process. In support of that, Snyder (2019) avowed that a semi-systematic review often looks at how research within a selected field has progressed over time or how a topic has developed across research traditions. It is therefore fitting to point out that digitisation of services or technological information and devices should be embraced within the social services (social work) fraternity.

Phase 2: Conducting the review - It was critical to outline the criteria for inclusion and exclusion for the articles to be reviewed. Snyder (2019) aver that it is critical that the actual selection of the sample can be done in a number of ways, depending on the nature and scope of the specific review. This implies that the nature and scope of the study was core during the review. To be specific, the approach in the conducting the review for this article was that abstracts were read first and making selections to see their relevance and then full-text articles were read later, before making the final selection. Another strategy used was scanning references of the selected articles to identify other articles that may potentially be relevant.

Phase 3: Analysis - After a literature review has been conducted, the analysis must ensue. Snyder (2019) opined that a standardized means of abstracting appropriate information from each article should be used. Snyder further postulates that data abstracted can be in the form of descriptive information, such as authors, years published, topic, or type of study, or in the form of effects and findings. It can also take the form of conceptualizations of a certain idea or theoretical perspective. Importantly, this should be done in concordance with the purpose and research question of the specific review, and the form will vary. Therefore, in this review, data analysed was in the form of findings (themes generated) from previous literature and conceptualisation of the new idea, that is, embracing digitisation in services delivery by social services professions as they work for social justice, sustainable livelihoods, and quality of life, to improve the socio-economic conditions of the poverty-stricken populations. In this study, thematic was employed as Braun and Clarke, (2006) posit that thematic analysis is a commonly used technique and can be broadly defined as a method for identifying, analyzing, and reporting patterns in the form of themes within a text.

Phase 4: Writing the review - It can be deduced that the purpose of a review of literature is primarily to summarise the knowledge around a specific question or topic, or to make recommendations that can support professionals and organisations make decisions about a specific intervention (Noble \& Smith, 2018). Snyder (2019) postulate that it is necessary to describe transparently the process of designing the review and the method for collecting literature, that is, how the literature was identified, analysed, synthesized, and reported by the author. Thereafter, the author can write the review. Therefore, it was crucial for this article that, findings emanating from the review are presented in the thematic matter as that was the best way to organise and critique the findings from the review. In a similar wavelength, Noble and Smith (2018) pointed out that a rigorous summary of the research is usually expected to identify the state of knowledge and gaps in the evidence related to their topic focus and to provide justification for the empirical work they subsequently undertake. It is for this reason that this article is written so as to identify gaps as the results of the digital divide and social exclusions as clearly argued correctly by Noble and Smith (2018) that reviews can highlight gaps in knowledge to guide future research.

\section{FINDINGS AND DISCUSSIONS}

It is unscientific and unprofessional to collate statements from different sources without making sense of it. This view is equally echoed by Carnwell and Daly (2001), who avow that reviewing the literature is not stamp collecting. A good review does not just summarize the literature, but discusses it critically, identifies methodological problems, and points out research gaps. Hereunder are the themes and subsequent discussions with a strong focus on the digital divide and social exclusion. This section is aimed at highlighting the role of the digital divide in social exclusion. The focus is on employment, socio-economic development, education, health, social services, and gender parity.

\section{- Employment}

Globalisation and digital technologies have transformed the labour system, from recruitment to the nature of work. Technology has become as essential as the postman was in the past because it enables job seeks to apply for jobs online (Suvankulov et al., 2012). Meeks (2017) avers that lack of technology and the internet has diminished prospects of job seekers finding employment as employers prefer online applications Digital divide threats exacerbate inequalities among marginalised groups in society by reducing their chance of attaining employment.

With the current conditions of the world ravaged by the scourge of COVID-19, it has entrenched the digital divide in the labour market. Skilled and professionals have seamlessly transitioned to remote working through the assistance of digital technologies such as Zoom, YouTube, facetime, and cloud computing systems to reduce the spread of COVID-19 (World Economic Forum [WEF], 2021). ICT infrastructure has been vital for employees working from home mainly in the educational institutions, and financial services industries such as banking and insurance companies. According to a report by McKinsey Global Institute on remote work (2020), skilled workers have been working successfully remotely, while low-skilled workers have been adversely affected by COVID19 induced lockdowns. These employees are limited by minimal, if any, digital skills, and areas in which they live. In addition, most of their job activities cannot be 
performed remotely and virtually as they are menial and labour intensive. The Covid-19 can have a debilitating impact on the plight of the semi-skilled and unskilled workforce.

\section{- Socio-economic development}

No sphere of human life has been spared by the permeation of the digital divide. Socio-economic development is one of the levers through which social problems can be eradicated. Wong et al. (2010) observe that the digital divide has adverse effects on social development because it restricts social mobility, and the ability to find employment-which is a precursor for social exclusion among vulnerable groups like the elderly, disenfranchised, and unemployed. Similarly, (Marianne, 2018) posits that the digital divide can have a worsening impact on people already faced with vulnerabilities and shocks in society. For example, the poor and unemployed have been marginalised since time immemorial, and the digital divide is worsening their plight in society. Digital technologies provide an opportunity to manage key infrastructure such as water and sanitation through integrating big data to detect challenges and offer expeditious decision-in in order to avoid infrastructure deterioration, and wastage, as is the case in low-income communities (Hoolohan et al., 2021). Due to the digital divide, marginalised people are faced with challenges such as lack of basic service i.e. water, sanitation, and roads infrastructure before the advent of digitalisation, thereby digitalisation compounds their challenges

The digital divide is an inhibitor of socio-economic development in society. It has been reported by WEF (2014), that each time there is an added $10 \%$ of internet penetration, there can be $1.2 \%$ increase on the Gross Domestic Product in emerging economies. The digital divide undermines economic growth, and can have a disastrous socio-economic impact. This happens because most of social, economic, political, and health activities such as social assistance, banking, voting, and booking doctor's appointments have been digitised. Barrow (2020) avers that the digitalisation of healthcare, education, and government services creates inequality because those without the internet are excluded from meaningfully participating in societal activities. It is observable that the modern society and economy systems are based on digitalisation, and thus lack of technology can hamper socio-economic development.

\section{- Education}

The role of technology in education had been incrementally phased in for years now, however, lockdowns implemented to mitigate the effects COVID-19 expedited the adoption of technology. Developing countries, as it is always the case, were slow to incorporate technology in education due to socio-economic conditions, but Covid-19 necessitated the move (Zalat et al., 2021). As Schools across the globe migrated their curriculums online in pursuit of salvaging academic calendars during the Covid-19 pandemic, the flagrance of inequalities is brought to the fore. Van Dijk (2020) is of the view that learners and students from the middle class and affluent backgrounds access digital education seamlessly than their counterparts from less fortunate backgrounds. It has been reported by Montoya (2020), that over 700 Million learners globally do not have access to the internet, thus they are excluded from online education. The digital divide brings an ugly face in education to an already wounded society. The United Nations' International Children's Fund $\underline{(2020)}$ reported that more than a billion children globally were unable to access education due to covid-19 lockdowns, which prevented physical contact. The authors are of the view that the number of learners digitally excluded is concerning and threatens the successful achievement of UN's Sustainability Development Goals (SDG).

Calarco (2020) avers that learners from low-income households face digital exclusion due to their parents and families' inability to fund online education in the midst of Covid-19 imposed restrictions. UN (2021) extrapolates that learners who are not digitally connected are unable to acquire skills relevant to the job market. Lack of access to education characterises social exclusion, and the digital divide has been denying learners from disadvantaged backgrounds the right to education. This can hinder their socio-economic development in the future as they may be further alienated. In addition to the threat that the digital divide poses on socio-economic development, it also constitutes a violation of a Constitutional right to education in some countries such as South Africa, India, and Sweden

\section{- Health}

The right to health is fundamental and advances have been made to move to digital health and telemedicine. Abaza \& Marschollek (2017) acknowledge that telemedicine and digital services such as text message (SMS) and mobile application (app) play a significant role in the delivery of health. In their review, Dillingham et al. (2018) found that SMS and apps have proven to be effective in the treatment of Human Immune Virus treatment. However, the emergence of COVID-19 has expedited the integration of technology in health. To curb the rapid spread of the virus, some health services are migrated online (World Health Organisation, 2020). This gave rise to mobile applications on patients can order their medication, the use of Artificial Intelligence applications such as the Iphone's Siri to provide information to patients, and the use of mobile to track and trace close contacts as far Covid-19 is concerned. In their survey on the digital divide in the era of Covid-19, Giasanti \& Veltro (2021) have found that the digital divide is an obstacle to the rollout of digital health services amid the Covid-19 pandemic. This is a huge setback at the time when traditional health approaches such as in-person consultation, individually or in groups were altered in pursuit of minimising the spread of Covid-19. 
The inability to access essential healthcare, especially during the Covid-19 pandemic, further entrenches social exclusion. Watts (2020) warns that the digital divide in the midst of the Covid-19 lockdown causes mental health problems because one is unable to access health information and counselling. The most painful part about Covid-19 is that socially ostracises people, and weigh down on support systems, thus the use of technology enables virtual interactions-which to provide much-needed psychosocial support for people infected and affected by the virus. On the contrary, digitally excluded people are left in a precarious health state because of the lack of digital health service in the midst of one of the worst health crises in human history. The unintended effect of digitalisation is that those without the internet are excluded from accessing lifesaving and enhance health services.

\section{- Social Services}

Digitalisation is transforming the face of social services in pursuit of improving efficacy. Digital technologies such as chatbots provide psychosocial support to people experiencing mental health challenges. A chatbot is an Artificial Intelligence application that enables conversations with users over the internet using texts or voice-through natural language process system-which enables it to process language used (Adamopoulou \& Moussiades, 2020; Khanna et al., 2015). However, due to the digital divide disenfranchised and marginalised people may be excluded from accessing critical mental health services. In addition, this can adverse effects on the quality of life.

The impact of the COVID-19 pandemic has a dire socio-economic impact on vulnerable people. In attempting to mitigate the socio-economic effects of the pandemic, the South Africa Government introduced special COVID-19 Social Relief of Distress (SRD) of R350 have been disbursed to an unemployed individual and are not receiving any other social assistance (Pienaar et al., 2021). In line with social distancing protocols, and the closure of the South African Social Security Agency (SASSA), SRD applications have been lodged online and telephonically. However, Edlmann et al.(2021) highlight that the application process has been exclusionary to people without a mobile phone, access to the internet, and low levels of digital literacy. This can result in delayed payments, which have adverse effects on recipients.

\section{- Gender inequalities}

The elimination of gender inequality is one of the paramount multilateral agreements widely supported globally. Patriarchal gender norms are still prevalent to date and the emergence and advancement of digital technologies should be used to amplify services to address this scourge. However, as reported by the UN, the digital divide thwarts efforts to empower women in pursuit of achieving gender equality (UN, 2021). ITU (2019) report on measuring digital development, $48 \%$ of women compared to $58 \%$ of men use the internet globally. The gender gap as far as internet usage has been closing in developed countries while widening in developing countries. According to a report on bridging the gender gap by OECD (2018), the digital divide is likely to adversely affect women than men due to their disadvantaged economic status in society. Women have historically been unfairly discriminated against for a multiplicity of reasons.

Van Dijk (2020) adds that women are susceptible to the digital divide because of their inferior financial and social positions. However, the literature highlights that women's lack of access to technology, and the internet cannot only be reduced to financial reasons but socio-cultural factors such as gender roles, patriarchy, and sexism (Johnson, 2010; GeertsemaSligh, 2006). The digital divide is set to further the exclusion of women from key societal institutions. For example, the gender gap inhibits women from accessing educational, employment, health, and financial opportunities in the digital age. This entrenches and perpetuates gender inequality in society, and affects their quality of life.

\section{Implications of the digital divide and social exclusion on Social Work}

Social Work is an academic and professional discipline aimed at engendering social change, problem-solving, social cohesion, empowerment, and enhancing social wellbeing (Nyaunda et al., 2020; Clarke, 2018; Zastrow, 2017).In the context of this paper, Social Work aims to combat social inequalities ravaging society, including the digital divide and social exclusion. It is the considered view of the authors that the digital divide creates a plethora of social problems which could require the intervention of Social Workers. Thus, it is in the best interest of Social Workers to understand the role of the digital divide in identifying social problems, implementing relevant programmes and services, monitoring thereof. Also, it is the role of social workers to advocate for the responsible use of technology for the service of humanity. In addition, Social Workers are not only expected to intervene in the abovementioned problems but they are also expected to influence policymaking. This is because there seems to be a dearth as far as the role of Social Workers in the advocacy of the humane use of technology. The digital divide is set to exacerbate unemployment, gender discrimination, and lack of access to health care and education among people in low-income countries (Mracek, 2018). Therefore, it is expected that the digital divide worsens social problems that Social Workers are at the forefront of solving. The nature of Social Work services and programmes needs to embrace the digital divide in pursuit of mitigating its effects on social development.

The digital divide has been treated as an ICT concept than a multidisciplinary phenomenon affecting all facets of society. Ragnedda (2019) cautions against reducing the digital divide as a technological issue as it overlooks the socio-cultural, educational, and political implications of the phenomenon. To this end, the authors argue that Social Work training and interventions need to address the digital divide because it is set to drive inequalities in the digital age. This will enable Social Workers to develop appropriate and relevant interventions aimed at addressing new forms of inequalities 
prevalent in the digital age. While Social Work like other professions are migrating services to digital platforms, provisions have to be made to ensure that no one is left behind. This requires Social Workers to advocate for policies and programmes aimed at closing the digital gap.

\section{- Towards digital inclusion}

This section proposes a solution to close the digital gap.

$\checkmark$ The rapid expansion of ICT infrastructure which supports 5G capabilities in developing countries, mainly in rural and township areas will enable digitally excluded people to access the internet, and participate in education, health, employment, and financial services, among others.

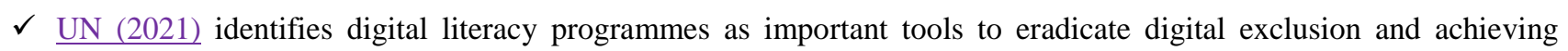
inclusivity.

$\checkmark$ Social Workers should drive policy reform, which advocates for access to digital technologies among the disenfranchised and deprived people. According to Helsper \& Galacz (2009), access to digital technology is a key aspect of enabling participation in the digital economy. For example, children can study online, they can apply for employment online, access social assistance and participate in the democratic process such as voting and policymaking. These can translate into meaningful participation in societal activities.

$\checkmark$ The Citizens Advice Scotland (2018) survey found that of lack of finances constituted the greatest barrier to access to technology, and the internet. There is a need for Government and Non-governmental Organisations to provide facilities where fee-free internet service can be accessed (Marianne, 2018). In the provision of such facilities, there is equitable distribution of between urban and rural communities.

\section{CONCLUSION}

Bearing in mind that this was a literature review on the connection between the digital divide and social exclusion, it became critical that a particular approach was adopted. Snyder (2019) avows that literature reviews play an important role as a foundation for all types of research. They can serve as a basis for knowledge development, create guidelines for policy and practice, provide evidence of an effect, and, if well conducted, can engender new ideas and directions for a particular field. As such, they serve as the grounds for future research and theory. Therefore, this paper sought to ascertain the connection between the digital divide and social exclusion. Discussions in this paper demonstrate that the digital divide curtails access to employment, health care, social services, education, and thwarts efforts to achieve gender equality among disenfranchised and downtrodden communities. From the above, it is deducible that the digital divide compounds social exclusion. This argument is upheld by Sanders \& Scanlon (2021), who avow that digital worsens social exclusion in which people are deprived of essential information and technologies which adversely affect their personal, social, political, and economic participation in society. The adverse impact of the digital divide and social exclusion poses a threat to global sustainable and inclusive socio-economic development.

The paper further assessed the implications of the digital divide on Social Work. It suggested that Social Workers are implored to embrace the digital divide as a new form of inequality causing social problems, and advocate for policies and programmes aimed at bridging the digital gap. Lastly, the paper offered possible solutions to address the digital divide such as policy reform, ICT infrastructure expansion, digital literacy programmes, reduction of internet access prices, and the introduction of subsidies aimed at enabling disadvantaged people in society to have access to the internet, and associated devices.

\section{AUTHORS CONTRIBUTIONS}

Molala Thomas developed an idea, did literature review, and wrote the first draft.

Makhubele JC did some literature review, reviewed the manuscript, and finalised it.

\section{REFERENCES}

1. Abaza, H., \& Marschollek, M. (2017). mHealth Application Areas and Technology Combinations: A Comparison of Literature from High and Low/Middle-Income Countries. Methods Inf Med, 56(1), 105-122. https://doi.org/10.3414/ME17-05-0003

2. Adamopoulou, E.,\& Moussiades, L. (2020). Chatbots: History, technology, and applications. Machine Learning with Applications, 2, 1-18. https://doi.org/10.1016/j.mlwa.2020.100006

3. Barrow, H. (2020). Digital, exclusion-covid-19 and social-inequalities. https://immigrationnews.co.uk/digitalexclusion-covid-19-and-social-inequalities/

4. Baumeister, R. F., \& Leary, M. R. (1997). Writing narrative literature reviews. Review of General Psychology, 1,311-320. https://doi.org/10.1037/1089-2680.1.3.311

5. Berafe, T.(2017). Assessing the causes and effects of social exclusion: The case of 'potmakers' in Yem Special Woreda Southern Nation, Nationalities and Peoples Region state in Ethiopia. African Journal of Political sciences and International Relations, 11(4), 68-83. 
6. Braun, V., \& Clarke, V. (2006). Using thematic analysis in psychology. Qualitative Research in Psychology, 3, 77-101. https://doi.org/10.1191/1478088706qp063oa.

7. Broadband commission. (2019). State of Broadband Report 2019. International Telecommunication Union.

8. Calarco, J. (2020). Online learning will be hard for kids whose schools close-and the digital divide will make it even harder for some of them. https://theconversation.com/online-learning-will-be-hard-for-kids-whoseschools-close-and-the-digital-divide-will-make-it-even-harder-for-some-of-them-133338

9. Campbell, B. R., Ingersoll, K.S., Flickinger, T.E., \& Dullingham, R. (2019). Bridging the digital health divide: toward equitable global access to mobile health interventions for people living with HIV. Expert Review of antiinfective Therapy, 17(3), 141-144. https://doi.org/10.1080/14787210.2019.1578649

10. Carnwell, R., \& Daly, W. (2001). Strategies for the construction of a critical review of the literature. Nurse education in practice, 1(2), 57-63. https://doi.org/10.1054/nepr.2001.0008

11. Citizens Advice Scotland. (2018). Disconnected: Understanding digital inclusion and improving access.

12. Clarke, S. (2018). Social Work as Community Development: A Management Model for Social Change ( $2^{\text {nd }}$ ed.). Routledge. https://doi.org/10.4324/9781315190648

13. Dillingham, R., Ingersoll, K., Flickinger, T. E., Waldman, A. L., Grabowski, M., Laurence, C., Wispelwey, E., Reynol, G., Conaway, M.,\& Cohn, W. F.(2018). Positive Links: a mobile health intervention for retention in HIV care and clinical outcome with 12-month follow-up. AIDS Patient care STDS, 32(6), 241-250. https://doi.org/10.1089/apc.2017.0303

14. GeertsemaSligh, M. (2006). Gender and the Digital Economy: Perspectives from the Developing World. Asian Journal of Communication, 16(4),440-442.

15. Giansanti, D.,\& Veltro, G. (2021). The Digital divide in the era of Covid-19:An investigation into an important obstacle to the access mHealth by the citizen. Health 2021, 9(371), 1-16. https://doi.org/10.3390/healthcare9040371

16. Gillwald, A ., Mothobi, O.,\& Rademan, B. (2018). The state of ICT in South Africa. Research ICT Africa

17. GSMA.(2020). The mobile Economy: Sub-Saharan Africa.

18. Edlmann,T., Senona,E., Torkelson.,\& Zembe, W.(2021). The Covid grant should be R585, so everyone can afford to eat. https://www.groundup.org.za/article/the-covid-19-grant-should-meet-the-food-poverty-linecurrently-at-r585-so-all-people-in-south-africa-can-afford-to-eat/

19. Helsper, E., \& Galacz, A .(2009). Understanding the links between social and digital inclusion in Europe . Changing Societies, Economies and Cultures, 146-178

20. Hoolohan, C., Amankwaa, G.,Browne, A. L., Clear, A., Holstead, K., Machen, R., Michalec, O.,\& Ward, S. (2021). Resocializing digital water transformations: outlining social science perspectives on the digital water journey. WIREs Water, 8(1), 1-17. https://doi.org/10.1002/wat2.1512

21. Independent Communication Authority of South Africa.(2020). The state of the ICT sector Report in South Africa.

22. International Telecommunications Union.(2019). Measuring digital development: facts and figures 2019.

23. International Telecommunications Union.(2020). Measuring digital development :facts and figures 2020.

24. Johnson, V. (2010). Women and the Internet: A Micro Study in Chennai, India. Indian Journal of Gender Studies, 17(1) ,151-163. https://doi.org/10.1177/097152150901700107

25. Khan, S.(2012). Social Exclusion. Governance and Social Resource Centre.

26. Khanna, A., Pandey, B., Vashishta, K., Kalia, K., Bhale, P., \& Das, T.(2015). A study of today's A.I. through chatbots and rediscovery of machine intelligence. International Journal of U-and eservice, Science and Technology, 8, 277-284. https://doi.org/10.14257/ijunesst.2015.8.7.28

27. Marianne, E. (2018). Building digitally inclusive communities. The Workshop.

28. McKinsey Global Institute.(2020). What's next for remote work: An analysis of 2,000 tasks, 800 jobs, and nine countries.

29. Meeks, K.R. (2017). The challenges of job hunting without the internet. http://longbeachmc.org/the-challengesof-job-hunting-without-the-internet/

30. Montoya, S. (2020). The importance of monitoring and improving ICT use in education post-confinement. http://uis.unesco.org/en/blog/importance-monitoring-and-improving-ict-use-education-post-confinement.

31. Mracek, K. (2018). What is the impact of digital divide? https://www.stlouisfed.org/openvault/2018/November/impact-of-digital-divide.

32. Noble, H., \& Smith, J. (2018). Reviewing the literature: choosing a review design. Evidence Based Nursing, 21(2), 39-41. https://doi.org/10.1136/eb-2018-102895

33. Nyaunda, L., Matlakala, F, K ., \& Makhubele, J.C. (2020). Factors Impeding the Participation of Rural Women in the Climate Change Discourse: A Requirement for Social Work Intervention. Southern African Journal of Social Work and Social Development, 32(3), 1-19. https://doi.org/10.25159/2708-9355/7771

34. Organisation for Economic Co-operation and Development (2016). Innovating Education and Educating for Innovation: The Power of Digital Technologies and Skills.

35. Organisation for Economic Co-operation and Development.(2018). Bridging the digital gender divide include, upskill, innovate. 
36. Pienaar, G., Davids, Y. D., Roberts, B., Makoae, M., \& Hart, T.(2021). The BIG question: COVID-19 and policy support for a basic income grant. Human Sciences Research Council.

37. Ragnedda, M. (2019). Reconceptualising the digital divide. In Mutsvairo, B., and Ragnedda, M., (2019) (eds)., Mapping the Digital Divide in Africa. A mediated Analysis (pp. 27-43). Amsterdam University Press. https://doi.org/10.2307/j.ctvh4zj72.6

38. Sanders, C. K., \& Scanlon, E. (2021). The digital divide is Human Rights: Advancing Social Inclusion through Social Work advocacy. Journal of Human Rights and Social Work, 6, 130-143. https://doi.org/10.1007/s41134020-00147-9

39. Snyder, H. (2019). Literature review as a research methodology: An overview and guidelines. Journal of business research, 104, 333-339. https://doi.org/10.1016/j.jbusres.2019.07.039

40. Suvankulov, F., Lau, C., \& Chau, F. (2012). Job searches on the internet and its outcome. Internet Research, 22(3), 298-317. https://doi.org/10.1108/10662241211235662

41. Soomro, K.A., Kale, U., Curtis, R., Akcaogola, M., \& .Bernstein, M. (2020). Digital Divide among higher education faculty. International Journal of Education Technology in Higher Education, 17(21), 1-16. https://doi.org/10.1186/s41239-020-00191-5

42. Stewaert, F.(2004).The relationship between horizontal inequality and social exclusion. Centre for Research on Inequality, Human Security, and Ethnicity.

43. Torraco, R. J. (2005). Writing integrative literature reviews: Guidelines and examples. Human Resource Development Review, 4, 356-367. https://doi.org/10.1177/1534484305278283.

44. Tranfield, D., Denyer, D., \& Smart, P. (2003). Towards a methodology for developing evidence-informed management knowledge by means of systematic review. British Journal of Management, 14, $207-222$. https://doi.org/10.1111/1467-8551.00375

45. Turianskyi,Y.(2020). COVID-19: Implications for the 'digital divide' in Africa. https://www.africaportal.org/ features/covid-19-implications-of-the-pandemic-for-the-digital-divide-in-africa/

46. United Nations.(2021). Leveraging digital technologies for social inclusion.

47. United Nations International Children's Fund. (2020). COVID-19: At least a third of the world's schoolchildren unable to access remote learning during school closures, new report says.

48. Van Dijk, J.(2005). The Deepening Divide. SAGE.

49. Van Dijk, J. (2020). Closing the digital divide: The Role of Digital Technologies on Social Development, WellBeing of All and the Approach of the Covid-19 Pandemic. Polity Press.

50. Watts, G. (2020). Covid-19 and the digital divide in UK. Elsevier. https://doi.org/10.1016/S25897500(20)30169-2

51. Webster, J., \& Watson, R. T. (2002). Analyzing the past to prepare for the future: Writing a literature review. Management Information Systems Quarterly, 26, 3.

52. Whittemore, R., \& Knafl, K. (2005). The integrative review: updated methodology. Journal of advanced nursing, 52(5), 546-553. https://doi.org/10.1111/j.1365-2648.2005.03621.X

53. Wong, G., Greenhalgh, T., Westhorp, G., Buckingham, J., \& Pawson, R. (2013). RAMESES publication standards: Meta-narrative reviews. BMC Medicine, 11, 20. https://doi.org/10.1186/1741-7015-11-20.

54. Wong, Y.C., Kwong, C., Chu Fung, J.Y., \& Ping Lee, V.W.(2010). Digital divide and social inclusion: policy challenge for social development in Hong Kong and South Korea. Journal of Asian Public Policy, 3(1), 37-52. https://doi.org/10.1080/17516231003634161

55. World Economic Forum. (2014). Delivering Digital Infrastructure Advancing the Internet Economy.

56. World Economic Forum.(2021). How skills development can bridge a growing divide among workers.

57. World Health Organisation.(2020). Covid-19 significantly impacts health services for noncommunicable disease.

58. Zalat, M. M., Hamed, M. S., \& Bolboi, S. A.( 2021). The experiences, challenges, and acceptance of e-learning as a tool for teaching during the Covid-19 pandemic among university medical staff. PLoS ONE, 16(3), 1-12. https://doi.org/10.1371/journal.pone.0248758

59. Zastrow, C. (2017). Introduction to Social Work and Social Welfare: Empowering people(2 ${ }^{\text {th }}$ ed.). Cengage Learning. 